\title{
Role of catecholamines in hypotensive response to dieting
}

\author{
R T JUNG, P S SHETTY, M BARRAND, B A CALLINGHAM, W P T JAMES
}

British Medical fournal, 1979, 1, 12-13

\section{Summary and conclusions}

The effect of dieting on blood pressure and catecholamine metabolism was assessed in 11 normotensive obese women by providing first a weight-maintenance regimen high in carbohydrate and then a low-energy diet. All dietary constituents other than carbohydrate were maintained constant throughout the 18-day study. The low-carbohydrate diet led within 48 hours to a $41 \%$ fall in the urinary output of 4-hydroxy-3-methoxy mandelate and a significant fall in systolic and diastolic blood pressure. Plasma noradrenaline concentrations also fell and the hypotensive effect of the diet continued despite a maintained total body sodium.

Thus the fall in blood pressure appeared to be mediated by changes in catecholamine metabolism independent of sodium intake. This may explain both the usefulness of weight reduction in hypertensive patients and the fainting that occurs in some normotensive obese subjects taking slimming regimens low in carbohydrate.

\section{Introduction}

The considerable evidence of a relation between obesity and hypertension has led to the emphasis on maintaining an ideal weight in hypertensive patients. Although the fall in blood pressure that occurs with weight $\operatorname{loss}^{1}$ is usually explained by a concomitant reduction in salt intake, Reisin et $a l^{2}$ reported a reduction in blood pressure in obese hypertensive patients on diet even when the salt intake remained unchanged. The underlying mechanisms in the pathogenesis of hypertension are still uncertain but overactivity of the sympathetic system has been implicated in a proportion of cases, since plasma concentrations of noradrenaline, adrenaline, and dopamine- $\beta$ hydroxylase have been found to be raised. ${ }^{3-5}$ This is not a universal finding, however, ${ }^{6}$ and it is not clear whether any of the reported abnormalities in catecholamine metabolism precede or accompany the development of hypertension. We have therefore attempted to explore some of the mechanisms underlying the control of blood pressure by studying normotensive obese women on a slimming regimen while maintaining their salt intake.

\section{Patients and methods}

Eleven obese women with weights of $82-130 \mathrm{~kg}$ (mean $98.4 \pm \mathrm{SE}$ of mean $4.0 \mathrm{~kg}$ ) and a mean age of $37 \cdot 4 \pm 4 \cdot 1$ years were investigated in a

MRC Dunn Clinical Nutrition Centre, Addenbrooke's Hospital, Cambridge CB2 1QE

R T JUNG, MB, MRCP, member of clinical scientific staff and honorary senior registrar

P S SHETTY, MD, commonwealth medical research scholar

W P T JAMES, MD, FRCP, assistant director and honorary consultant physician

Department of Pharmacology, University of Cambridge

M BARRAND, PHD, senior assistant in research

B A CALLINGHAM, PHD, lecturer metabolic ward for at least 18 days. Initially they were equilibrated for seven days on a weight-maintenance, high-energy diet (HED) calculated to provide $40 \mathrm{kcal}(0 \cdot 17 \mathrm{MJ}) / \mathrm{kg}$ of desirable weight. Desirable weight was defined as that corresponding to the midpoint of the medium-frame-size weight range as listed by the Metropolitan Life Insurance Company. ${ }^{7}$ They were then given a low-energy diet (LED) providing only $9.2 \mathrm{kcal}(0.04 \mathrm{MJ}) / \mathrm{kg}$ of desirable weight for the rest of the study. Both diets were identical in their content of protein $(80 \mathrm{~g})$, fat $(10 \mathrm{~g})$, minerals, and vitamins. The energy restriction was achieved by decreasing carbohydrate intake only. Sodium intake was $52 \mathrm{mmol}(\mathrm{mEq}) / 24 \mathrm{~h}$ on the HED and $51 \mathrm{mmol} / 24 \mathrm{~h}$ on the LED; the extra starch used in the HED contained a small amount of sodium. Blood pressure was measured supine with a sphygmomanometer using a wide cuff by a trained nurse who was unaware of the purpose of the study. Measurements were taken at the same time each morningnamely, within half an hour of awakening and before the patient go out of bed. Samples of venous blood were taken between 830 and 930 am after a 10-hour fast. A 19-gauge Abbott butterfly cannula was inserted into a brachial vein and kept open with a few $\mathrm{ml}$ of $3.8 \%$ sodium citrate $B P C$. The subjects lay supine with the cannula inserted for an hour before the blood sample for analysis was withdrawn. Plasma catecholamines were measured by a radioenzymatic assay. ${ }^{8}$ Twenty-four-hour urine samples were collected daily into bottles containing $4 \mathrm{~N} \mathrm{HCl}$ as preservative. Urinary sodium was measured by flame photometry, and urinary 4-hydroxy-3-methoxy mandelate (HMMA) by a spectrophotometric method. ${ }^{9}$

Ethical approval was given by the unit's ethical committee. Paired $t$ tests were used for statistical analysis.

\section{Results}

While taking the HED the 11 obese patients maintained weight, and their supine systolic and diastolic pressures did not alter significantly during the seven-day equilibration period (systolic $129 \pm 3 \mathrm{~mm} \mathrm{Hg}$ on day $1 v 127 \pm 3 \mathrm{~mm} \mathrm{Hg}$ on day 7 ; diastolic $84.3 \pm 2.3 \mathrm{~mm} \mathrm{Hg}$ on day $1 v 84.4 \pm 1.4 \mathrm{~mm} \mathrm{Hg}$ on day 7). On beginning the LED both systolic and diastolic pressures rapidly declined. The decline in systolic pressure attained significance within 48 hours $(118 \pm 4 \mathrm{~mm} \mathrm{Hg}$ significance. of difference from pressure on last day of HED : $P<0.05$ ), while the fall in diastolic pressure was significant by the third day $(80.0 \pm 1.7 \mathrm{~mm} \mathrm{Hg} ; \mathrm{P}<0.05)$. From the third day of semi-starvation there was no further appreciable change in systolic pressure, but the diastolic pressure continued to decline $(76.0 \pm 1.8 \mathrm{~mm} \mathrm{Hg}$ on day 11 of the LED; $\mathbf{P}<0.05)$. Supine pulse rate was unchanged on the weight-maintenance regimen but showed an appreciable decrease on the LED $(70 \cdot 0 \pm 2.9$ beats/min on the last day of the HED $v 63.6 \pm 3.3$ beats/min on day 11 of the LED; $P<0.05)$. The mean loss of weight during the 11 days of semi-starvation was $5.4 \mathrm{~kg}$.

Sodium balance was calculated by subtracting from the intake urinary losses and estimated amounts lost daily in sweat $(2.5 \mathrm{mmo}$ (mEq)) and stools ( $1.5 \mathrm{mmol})$. Total body sodium increased by 79.1 $\mathrm{mmol}$ in the final five days of the high-carbohydrate diet. On days 2-6 of the LED sodium excretion increased but total body sodium remained in excess of initial values by $30.8 \mathrm{mmol}$ (see figure). After day 6 on the LED urinary losses were again less than the intake, and the calculated total body sodium was $+63.6 \mathrm{mmol}$ in excess of the initial values by day 11 of the LED.

Plasma noradrenaline concentrations measured while the patients were supine declined from $1 \cdot 00 \pm 0.24 \mathrm{nmol} / 1(0 \cdot 17 \pm 0.04 \mathrm{ng} / \mathrm{ml})$ on the HED to $0.41 \pm 0.12 \mathrm{nmol} / 1(0.07 \pm 0.02 \mathrm{ng} / \mathrm{ml})(\mathrm{P}<0.05)$ by the 11 th day of the LED. No significant change in plasma adrenaline was found $(0.22 \pm 0.05 v 0.16 \pm 0.05 \mathrm{nmol} / 1 ; 0.04 \pm 0.01 v 0.03 \pm 0.01$ $\mathrm{ng} / \mathrm{ml}$ ). Although the 24-hour excretion of urinary HMMA was maintained on the HED $(23.9 \pm 2 \cdot 1 \mu \mathrm{mol} / 24 \mathrm{~h}(4 \cdot 7 \pm 0.4 \mathrm{mg} / 24 \mathrm{~h})$ on the first day and $22 \cdot 1 \pm 2 \cdot 4 \mu \mathrm{mol} / 24 \mathrm{~h}(4 \cdot 4 \pm 0.5 \mathrm{mg} / 24 \mathrm{~h})$ on the last day of the HED), the urinary clearance of HMMA had fallen to basal values within 48 hours $(16.0 \pm 1.8 \mu \mathrm{mol} / 24 \mathrm{~h}(3.2 \pm 0.4 \mathrm{mg} / 24 \mathrm{~h})$; $\mathrm{P}<0.02)$. The adjustment in HMMA output to the LED was complete within this time, there being no further decline as weight loss progressed (figure). 


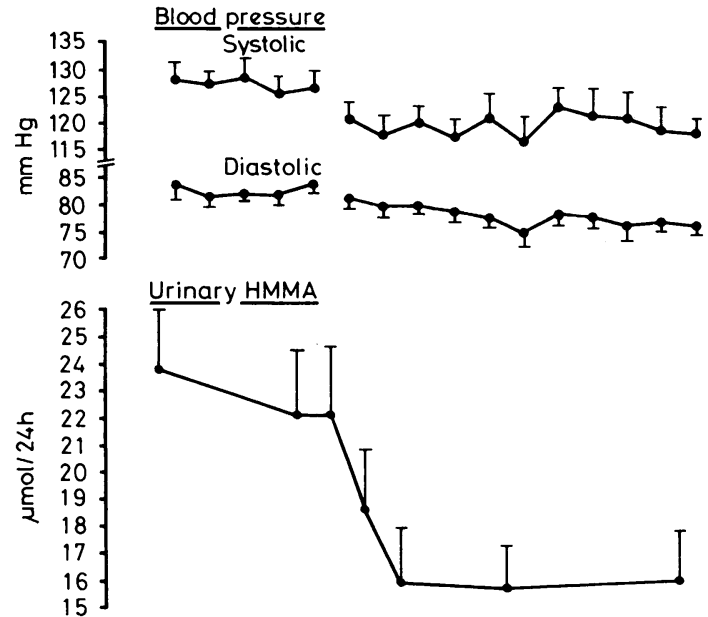

Apparent net balance of body sodium

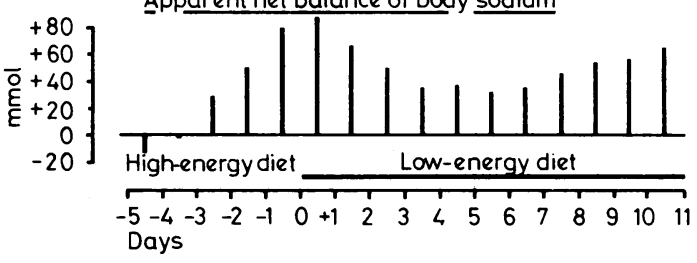

Mean ( \pm SE of mean) morning blood pressure, 24-hour urinary output of 4-hydroxy-3-methoxy mandelic acid (HMMA), and total body sodium calculated daily in 11 obese women while taking high- and low-energy diets. HMMA and body sodium plotted at midpoint of each 24hour cycle.

Conversion: SI to traditional units-Urinary HMMA $1 \mu \mathrm{mol} / 24 \mathrm{~h} \approx 0 \cdot 2 \mathrm{mg} / 24 \mathrm{~h}$. Body sodium: $1 \mathrm{mmol}:=1 \mathrm{mEq}$.

\section{Discussion}

Factors that may be relevant in the hypotensive effect of semi-starvation include the effects of rest, a lower sodium intake, a reduced supply of energy, and perhaps weight reduction itself. Our patients were encouraged to remain active throughout their stay in the metabolic ward, and no appreciable reduction in blood pressure was found during the initial period on the HED when the maximum effect of changing from a home to hospital environment would have been apparent. Furthermore, the rapid and pronounced reduction in both systolic and diastolic pressures within 72 hours of semi-starvation seemed too great to be accounted for by a subtle change in activity: no alteration in physical activity was apparent, and this was confirmed by monitoring activity throughout the 24 hours by the activity diary technique.

The natriuretic phase which occurred early in semi-starvation resulted in a short-lived negative sodium balance, which could reduce blood pressure. Total body sodium, however, had already increased in response to the high-carbohydrate feeding, and after an initial decrease on the LED there was a further small rise. Thus although the increased sodium output on days 2-6 of the LED may have lowered the blood pressure, the initial calculated increase in total body sodium on the HED more than compensated for this sodium loss. It seems unlikely that the temporary change in sodium balance could have maintained the reduction in blood pressure throughout the period on the LED.

In man a pronounced fall in sodium intake increases the concentration of circulating catecholamines, ${ }^{10}$ and a rise in plasma noradrenaline has been reported during starvation. ${ }^{11}$ Fasting animals not given sodium supplements also have raised catecholamine concentrations, ${ }^{12}$ but if sodium intake is maintained then starvation leads to a fall in noradrenaline turnover. ${ }^{13}$ If the hypotensive effect of semi-starvation resulted from a fall in plasma volume or a low sodium intake, then a compensatory rise in catecholamines would have been expected.

A primary change in both catecholamine metabolism and circulating noradrenaline offers a more rational explanation for the hypotensive effect of slimming. Our finding that the plasma concentration of noradrenaline falls and that there is an immediate reduction in urinary HMMA on the LED suggests that carbohydrate or energy intake can by itself influence catecholamine turnover and hence blood pressure. The urinary output of HMMA necessarily responds more slowly than the events determining catecholamine catabolism, since urinary output reflects the clearance of HMMA from the body pool. The natriuretic effect of semi-starvation may be mediated through hormones such as glucagon ${ }^{14}$ and also through renal resistance to mineralocorticoid activity. ${ }^{15}$ The natriuretic effect of restricting carbohydrates, however, may also be mediated by the fall in catecholamines, since it has been found that plasma renin activity also falls ${ }^{15}$ (our unpublished observation), and this fall will increase sodium excretion. ${ }^{15}$ Thus the hypotensive consequence of dieting may result from several effects of catecholamines : a direct action on vascular adrenergic receptors, a reduction in the renin-mediated production of the potent vasoconstrictor angiotensin, and the natriuretic effect of a lower renin output.

It has been known for many years that slimming can benefit hypertensive patients, and this has recently been confirmed, ${ }^{2}$ independent roles for sodium restriction and dieting having been established in the management of overweight hypertensive patients. Our results provide an explanation for the beneficial effect of dieting. Reduced catecholamine turnover may also explain the postural hypotension that occurs in many obese patients starting on a very restricted carbohydrate intake. Hypoglycaemia is rarely found in these subjects, and fainting may occur while supplementing the diet with sodium. We have observed that a choice of a relatively high-carbohydrate but energy-restricted diet can minimise the hypotensive effect of these slimming regimens. These clinical observations suggest that carbohydrate per se influences blood pressure via its effects on catecholamine metabolism, but the specificity of the carbohydrate effect requires further assessment of the influence of fat and specific carbohydrates on catecholamine responses.

We thank Mrs T Saich for expert technical work, Mrs E Blackwell for preparing the diets, and Sister J Mynott and staff on Hatton ward, Addenbrooke's Hospital, for inpatient care.

\section{References}

${ }^{1}$ Ramsay, L E, et al, British Medical fournal, 1978, 2, 244.

${ }^{2}$ Reisin, E, et al, New England fournal of Medicine, 1978, 298, 1.

${ }^{3}$ Sever, P S, et al, Lancet, 1977, 1, 1078.

${ }^{4}$ Franco-Morselli, R, et al, British Medical fournal, 1977, 2, 1251.

${ }^{5}$ Geffen, L B, et al, Clinical Science, 1973, 44, 617.

${ }_{6}^{6}$ Lake, C R, et al, Circulation Research, 1977, 41, 865

7 Metropolitan Life Insurance Company, New York, Statistical Bulletin, 1960, 41, February, p 6; March, p 7.

${ }^{8}$ Callingham, B A, and Barrand, M A, in Hormones in Blood, ed C $\mathrm{H}$ Gray and V H T James, 3rd edn. London and New York, Academic Press. In press.

9 Pizano, J J, Craut, J R, and Abraham, D, Clinica Chimica Acta, 1962, 7, 285.

${ }^{10}$ Kelsh, R C, et al, fournal of Laboratory and Clinical Medicine, 1971, 77, 267.

11 Christensen, N J, Diabetes, 1974, 23, 1.

12 Herrera, E, Knopp, R H, and Freinkel, N, Endocrinology, 1969, 84, 447.

${ }^{13}$ Landsberg, L, and Young, J B, New England fournal of Medicine, 1978, 23, 1295.

14 Saudek, C D, Boulter, P R, and Arky, R A, fournal of Clinical Endocrinology and Metabolism, 1973, 36, 761.

${ }^{15}$ Boulter, P R, Spark, R F, and Arky, R A, fournal of Clinical Endocrinology and Metabolism, 1974, 38, 248.

(Accepted 25 October 1978) 